\title{
Lymphatic Elephantiasis in One Neglected African Country-Democratic Republic of Sao Tome e Principe
}

\section{Fan $\mathrm{CK}^{1,2,3 *}$, Chang $\mathrm{YT}^{4}$, Hsu $\mathrm{CH}^{4}$, Liao $\mathrm{CW}^{1,2}$, Huang $\mathrm{YC}^{1,2}$, Chi $\mathrm{LH}^{4}$ and da Costa Âdos $\mathrm{S}^{5}$}

${ }^{1}$ Department of Parasitology, College of Public Health and Nutrition, Taipei Medical University, 250 Wu-Xing Street, 11031 Taipei, Taiwan ${ }^{2}$ Center for International Tropical Medicine, College of Medicine, Taipei Medical University, 250 Wu-Xing Street, 11031 Taipei, Taiwan

${ }^{3}$ Global Health and Development Master Program, College of Public Health and Nutrition, Taipei Medical University, 250 Wu-Xing Street, 11031 Taipei, Taiwan ${ }^{4}$ Taiwan Medical Mission in São Tomé, São Tomé C.P. 839, Democratic Republic of São Tomé and Príncipe, Taiwan

${ }^{5}$ Ministry of Health and Social Affairs, São Tomé C.P. 23, Democratic Republic of São Tomé and Príncipe, Taiwan

The Democratic Republic of Sao Tome e Principe (DRSTP) consists of the two islands of Sao Tome and Principe and a number of smaller islets in the Gulf of Guinea. Sao Tome lies approximately 180 miles from Gabon on the West African coast, and the equator crosses its southern tip. The climate is tropical with two rainy seasons. The total number of inhabitants in the DRSTP is estimated to be 160,000 . Due to the suitable climate, many neglected tropical parasitic diseases e.g., intestinal parasites, Schistosoma intercalatum, and Toxoplasma gondii have been found endemic in DRSTP $[1,2]$. Since arthropodborne parasitic diseases e.g., falciparum malaria has been long seriously endemic, the infection rate of malaria has been greatly reduced from $25 \%$ in year of 2000 to less than $3 \%$ in year of 2008 in DRSTP through intensive insecticide spray; and that the achievement was accomplished by the efforts of Taiwanese experts who were financially supported by Taiwan government [3-5]. Nevertheless, Lymphatic Elephantiasis (LE) cases can be still found in some inhabitants (Figure 1) who have been living in Sao Tome Island for more than 25 years; whereas LE was ignored and overshadowed by malaria for a long time in DRSTP. Although Ruiz et al. [6] has indicated such elephantiasis in STP

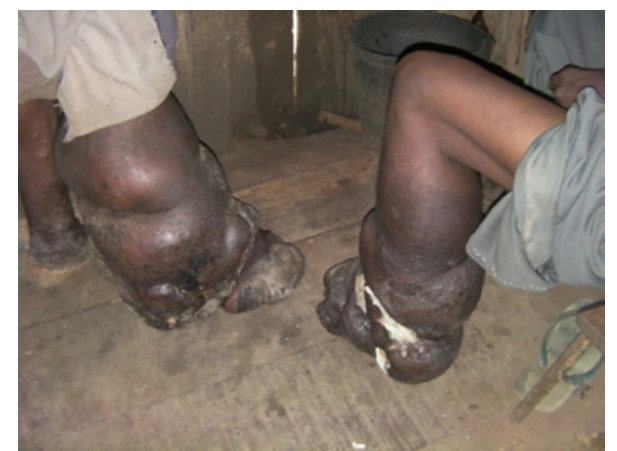

Figure 1: Elephantiasis in lower extremities of right and left legs in twin brothers, respectively.

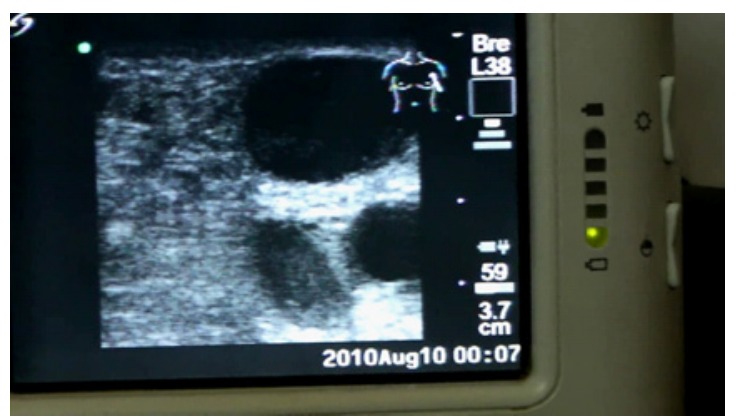

Figure 2: Filarial dance sign in left inguinal region as detected by Ultrasonography. people is possibly produced by deposits of inorganic materials in the lymph node of the lower extremities which is alternatively named of Podoconiosis; it is evidenced that in fact filarial lymphatic elephantiasis (FLE) co-exists with Podoconiosis in DRSTP because we found one FLE case in STP reporter who has filarial dance sign [7] in left inguinal region as detected by Ultrasonography with a linear array transducer at 7.5 MHz (Sonoma Health Products, Inc., CA, USA) (Figure 2). Comprehensive epidemiological investigations for STP inhabitants are urgently needed to elucidate whether FLE is commonly transmitted among rural areas. Although FLE has been regarded by World Health Organization as important Neglected Tropical Disease (NTD); until 2011, WHO designated podoconiosis as one of the 20 NTDs [8]. Since the different infection routes for Podoconiosis and FLE, measures against Podoconiosis is to prevent inhabitants walking on the soil with bare feet from the skin being penetrated by inorganic materials derived from alkaline volcanic rock; while measures against FLE including avoid mosquito's biting and take Albendazole regularly.

\section{References}

1. Chu T, Liao C, Huang Y, Chang Y, Costa A, et al. (2012) Prevalence of Schistosoma intercalatum and S. haematobium Infection among Primary Schoolchildren in Capital Areas of Democratic Republic Of São Tomé and Príncipe, West Africa. Iran J Parasitol 7: 67-72.

2. Fan CK, Lee LW, Liao CW, Huang YC, Lee YL, et al. (2012) Toxoplasma gondii infection: relationship between seroprevalence and risk factors among primary schoolchildren in the capital areas of Democratic Republic of São Tomé and Príncipe, West Africa. Parasit Vectors 5: 141.

3. Tseng LF, Chang WC, Ferreira MC, Wu CH, Rampão HS, et al. (2008) Rapid control of malaria by means of indoor residual spraying of alphacypermethrin in the Democratic Republic of São Tomé and Príncipe. Am J Trop Med Hyg 78: 248-250.

4. Teklehaimanot HD, Teklehaimanot A, Kiszewski A, Rampao HS, Sachs JD (2009) Malaria in São Tomé and principe: on the brink of elimination after three years of effective antimalarial measures. Am J Trop Med Hyg 80: 133-140.

5. Lee PW, Liu CT, do Rosario VE, de Sousa B, Rampao HS, et al. (2010) Potential threat of malaria epidemics in a low transmission area, as exemplified by São Tomé and Príncipe. Malar J 9: 264.

6. Ruiz L, Campo E, Corachán M (1994) Elephantiasis in São Tomé and Príncipe. Acta Trop 57: 29-34.

*Corresponding author: Fan CK, Department of Parasitology, Center for International Tropical Medicine, College of Medicine, Taipei Medical University, 250 Wu-Xing Street, 11031 Taipei, Taiwan, E-mail: tedfan@tmu.edu.tw

Received February 20, 2013; Accepted March 20, 2013; Published March 25, 2013

Citation: Fan CK, Chang YT, Hsu CH, Liao CW, Huang YC, et al. (2013) Lymphatic Elephantiasis in One Neglected African Country-Democratic Republic of Sao Tome

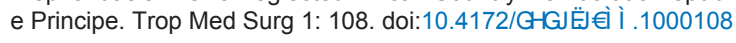

Copyright: ( 2013 Fan CK, et al. This is an open-access article distributed under the terms of the Creative Commons Attribution License, which permits unrestricted use, distribution, and reproduction in any medium, provided the original author and source are credited. 
Citation: Fan CK, Chang YT, Hsu CH, Liao CW, Huang YC, et al. (2013) Lymphatic Elephantiasis in One Neglected African Country-

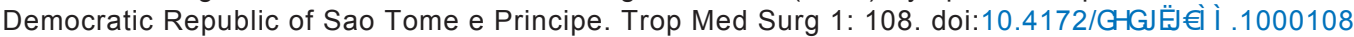

Page 2 of 2

7. Mand S, Marfo-Debrekyei Y, Dittrich M, Fischer K, Adjei O, et al. (2003) Animated documentation of the filaria dance sign (FDS) in bancroftian filariasis. Filaria J 2: 3 .
8. Korevaar DA, Visser BJ (2012) Podoconiosis, a neglected tropical disease. Neth J Med 70: 210-214. 